\title{
Comparative Study on the Economic Efficiency of Rapeseed Culture in Conventional and Organic Systems
}

\author{
Elena ȘURCĂ $\breve{A}^{*}$ \\ Research Institute for Agriculture Economy and Rural Development, Bucharest, Romania \\ *corresponding author: surca.elena@iceadr.ro \\ Bulletin UASVM Horticulture 75(1) / 2018 \\ Print ISSN 1843-5262, Electronic ISSN 1843-536X \\ DOI:10.15835/buasvmcn-hort: 000117
}

\begin{abstract}
From an economic point of view, efficiency implies the use of resources, of any kind, at maximum efficiency, or else the relation between effect and effort is over unit. In any kind of activity economic efficiency is the basis for its start. In the present paper, the level of economic efficiency for rape crops will be determined, according to two technological systems: conventional and organic. The revenue structure, and especially the expenditure, will be found in the income and expenditure budget of the culture. We will compare the value of production, production costs, but also yield or rate of return. In the continuation of the study, a set of indicators of economic efficiency will be calculated for each crop system, which will be subjected to a mirror analysis, to determine the feasibility of rapeseed crops as accurately as possible. Finally, the results will be presented, the profitability of the crop according to the system, the level of the profit and the recommendations regarding the future way of growing the rapeseed.
\end{abstract}

Keywords: economic efficiency, organic, feasibility, profitability, rape seed

\section{Introduction}

Before comparing the two agricultural production systems, it is necessary to define them, thus, according to Gomiero et al. (2011) organic farming can be described as agriculture based on a series of organic farming practices with the aim of minimizing the impact on the environment and the food industry, preserving the long-term soil sustainability and minimizing the use of nonrenewable resources, this plays an important role in improving soil fertility by renouncing the use of phytosanitary chemicals or genetically modified organisms, as well as other compounds used for agro-technical purposes. On short resume, organic farming is based on a well-founded principle in which health is placed above all, namely the health of the soil, plants, animals, implicitly of the planet and its inhabitants. While conventional agriculture has a major objective of maximizing productivity and, implicitly, profitability. This type of agriculture emphasizes the industrialized system by using mechanics, monoculture and fertilizers and/or pesticides (Ursu et al., 2017).

The current situation of the two types of agriculture, according to the "Organic Farming Research Institute (Germany: FiBL) in 2013, organic farming was practiced in 170 countries that provide data on it, and cultivated areas, including those that were converted, amount to the value of 43.1 million hectares. At the continental level, Oceania has the largest organic farming population with $40 \%$, followed by Europe by $27 \%$, followed by Latin America with 15\%, Asia (8\%), North America (7\%) and the last place is Africa with only $3 \%$ of the total organic area.

According to the same source at European level, around 11.5 million hectares were cultivated in 2013, in terms of organic farming, over the past and half decade, organic farming has been rising in many of the world's states, but according to Eurostat 2013, only $4 \%$ of the land is occupied by organic culture. 
According to De Ponti et al. (2012) in the paper entitled " The crop yield gap between organic and conventional agriculture," they affirm that the key points in determining the place of organic farming and the role played by it in the future will be determined by the economic competitiveness of conventional farming, the productivity of organic farming, and the demand for agricultural and livestock products for the daily diet of humans and animals.

In Romania, there is an area of 288,261 hectares where organic farming is practiced, so Romania is ranked 11th in the European Union in terms of organically cultivated area, from the entire European organic agricultural area, Romania holds about $2.83 \%$.

At national level, there are 15,423 organic farming operators. (Şurcă and Petre, 2016). From all these data it results that in Romania organic agriculture is appreciated and presents a future with perspectives.

Regarding conventional agriculture, Romania is positioned in the first 6 countries according to the agricultural area, as presented by Eurostat.

One of the most important cultures that is found at national level in organic and conventional farming systems is rapeseed which has a growing interest for the farmers, given the potential for this crop and the level of market demand, which is quite high; knowing that some buyers conclude contracts with farmers for the production of rapeseed obtained before its cultivation.

The importance of this crop is given by the product obtained from the processing of rapeseed and rapeseed oil; it places crops on the fifth place in the oilseeds ranking in terms of production (Bran, 2015).

Another aspect of the importance of culture is given by the rapeseed oil, especially its field of use, such as industrial or food. Rape cakes, obtained from the processing and obtaining of oil, are excellent fodder with a good nutritional value, being rich in carbohydrates, proteins and mineral salts (Bunting, 1981).

McGregorlb (2009) consider that rape is also melliferous plant, being the first consistent source of honey for the apiculture sector, providing about 50 pounds of honey per hectare.

For these reasons, especially those in the food sphere, both human and animal, in both agriculture systems conventional and organic, must be fairly addressed. With all these aspects of the importance of culture, it should not be forgotten that any production activity seeks to obtain a gain from it. Thus, economic profitability is essential to continue the production process, establishing the level of profitability of rape crops in conventional and organic systems, comparing it and advising farmers on success and risk.

\section{Materials and methods}

In the first part of the paper a qualitative and quantitative research will be carried out on the statistical data from the National Institute of Statistics and Eurostat to create a vision of the surfaces and productions obtained in the two systems of rapeseed culture.

In the second part, the income and expenditure budget of the crop is used, the tool is used to assess the value of the production (both main and secondary) and the structure of the production expenses, to which are added the net income and the rate of profitability. This budget was taken over from the ADER project 13.1.2 "Technical and economic costing of production costs and estimates of the prices for wheat, maize, sunflower, rape, soybean, sugar beet, rice, hemp, hop , Tobacco, Potato for Conventional Agriculture and Organic Farming "managed by the Research Institute for the Economy of Agriculture and Rural Development, the project runs between 20152018, takes place in stages and the results of the stages are presented to the public on the official website of the institute. The budgetary data presented in this article were processed from the above-mentioned ADER project from the number four phase (Analysis of the Economic Efficiency of Vegetable Production for Conventional Farming and Organic Farming 2015-2016) which had as a general objective the cost management for conventional agriculture and organic. The specific objectives of the phase have led to as many simulations of possible scenarios as possible in determining the profitability threshold, so the research carried out aims to provide the best information regarding the economic efficiency indicators for the two agricultural systems.

The paper has a methodological, synthetic character, emphasizing the theories, concepts and models of technical and economic analysis, the presentation of the indicators used in the appreciation of the economic efficiency of the 
production activity (indicators reflecting the economic effort - the consumption of working time, production indicators, indicators reflecting the economic effect - average production, total incomes, average price on the farm, indicators reflecting the actual economic efficiency - labor productivity, production cost, gross profit, profit rate, production costs per 1000 lei income material expenses per 1000 lei of income, etc.), the profitability threshold as well as the effect of the average production and the price of capitalization on the gross margin. Optimal solutions have a specific character. Through studies and analyzes we are pursuing the ways of increasing the economic efficiency and determining this efficient. The research was based on descriptive research (web report of ADER 13.1.2, Phase 4, MARD).

About the economic indicators on the efficiency and feasibility of the rapeseed culture according to the system (organic or conventional) they will be calculated, so quantitative indicators such as: Gross margin, expenses per 1000 lei main production, labor productivity and the threshold Profitability (Isfanescu et al., 2015).

\section{Results and discussions}

In Romania, about 368 thousand hectares of rapeseed were grown in 2015 , less by $9.5 \%$ compared to the previous year, but over the entire analyzed period, the area with rapeseed grew on average by $20 \%$ (Tab. 1 ).

If we refer to the total production of rapeseed, there is a very large increase, averaging $53.6 \%$ in the period 2010-2015, reaching 2020 tons in the year 2015. The largest rapeseed production was recorded in 2014, exceeding the 1 million tons (1.06 million tons) threshold.

Depending on the two indicators, average yields per hectare of rapeseed were calculated, ranging from 1490 kilograms per hectare (2012) to $2604 \mathrm{~kg} / \mathrm{ha} \mathrm{(2014).}$

As can be seen in Figure 1, mean rapeseed production increased by an average of 10 percent, reaching the peak in 2014 and in 2015 the average yield was almost 2500 kilograms per hectare. This

Table 1. Evolution of surface and rapeseed yields

\begin{tabular}{ccccccc}
\hline Specifications & $\mathbf{2 0 1 0}$ & $\mathbf{2 0 1 1}$ & $\mathbf{2 0 1 2}$ & $\mathbf{2 0 1 3}$ & $\mathbf{2 0 1 4}$ & $\mathbf{2 0 1 5}$ \\
\hline Surface area (thousand ha) & 537.3 & 392.7 & 105.3 & 276.6 & 406.7 & 367.9 \\
\hline Total production (thousand t) & 943 & 739 & 157.5 & 666.1 & 1059.1 & 919.5 \\
\hline Average yield (kg/ha) & 1755 & 1882 & 1496 & 2408 & 2604 & 2499 \\
\hline
\end{tabular}

Source: INS

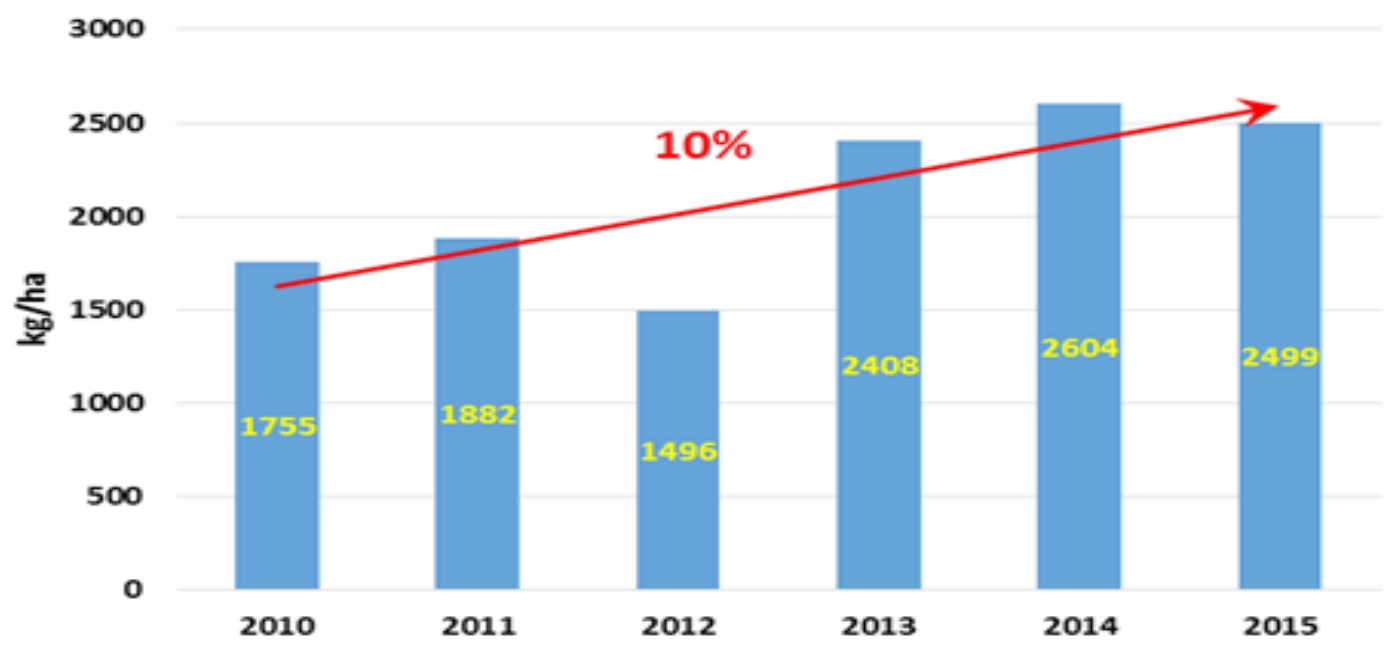

Figure 1. Medium production of rapeseed Source: INS data processing 
Table 2. Situation of organic rapeseed areas and yields

\begin{tabular}{ccc}
\hline Specifications & $\mathbf{2 0 1 4}$ & $\mathbf{2 0 1 5}$ \\
\hline Organic Surface (ha.) & 16065 & 10589 \\
\hline Share \% & 3.95 & 2.88 \\
\hline Organic production (t) & 28031 & 20401 \\
\hline Share \% & 2.65 & 2.22 \\
\hline Average organic production. (Kg / ha) & 1745 & 1927 \\
\hline
\end{tabular}

Source: Eurostat

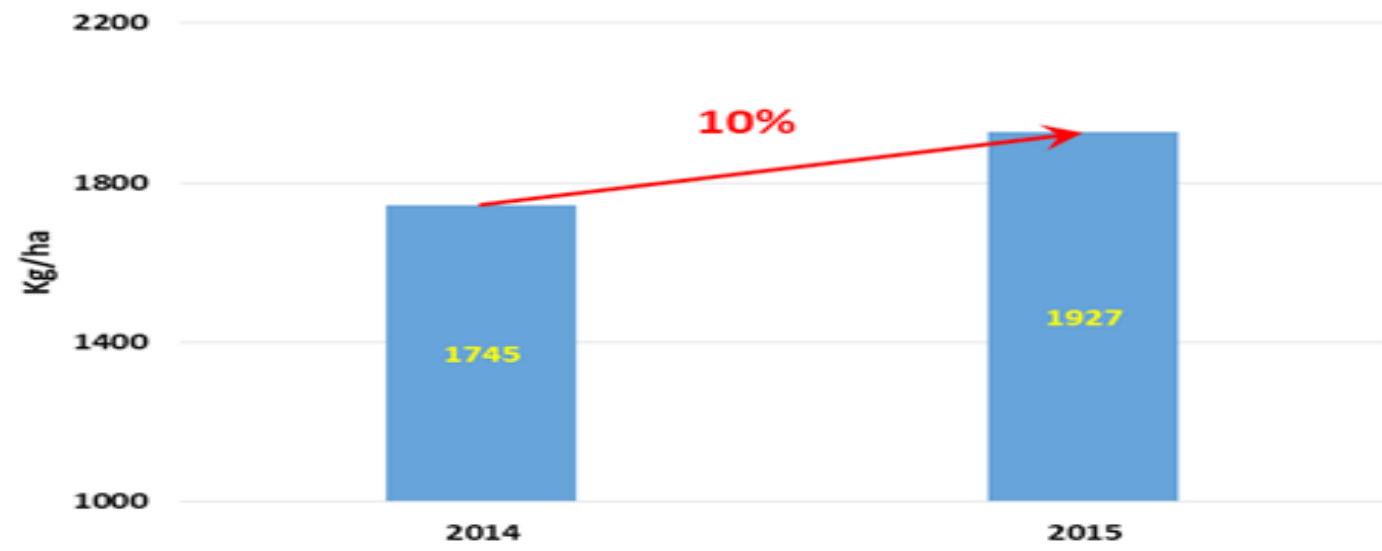

Figure 2. Medium production of organic rape Source: Eurostat data processing

increase is due to the modernization of technology and cultivation technology.

In the case of organic farming, data was taken from Eurostat, but these were only found for the years 2014 and 2015, so we cannot talk about an evolution, but we can make some comparisons.

In 2014, the area planted with organic rapeseed was 16065 hectares, decreasing by $34 \%$ in the following year, reaching 10.6 thousand hectares, thus reducing the share of surface cultivated with rapeseed in the system organically occupies the total area dedicated to this culture, from $3.95 \%$ in 2014 to $2.88 \%$ in 2015 , representing a decrease of $1.07 \%$.

The total production of organic rape, followed the trend of the area, as expected, so as compared to 2014, it diminished in the following year by $27.2 \%$, reaching 20.4 thousand tons. By doing a similar analysis to the ratio of the organic rapeseed area in the total area planted with rape, the organic production in 2014 was $2.65 \%$ of the total harvested rapeseed and in 2015 this weight was $2.22 \%$, which means a reduction of $0.43 \%$.

Depending on the two above mentioned indicators, a third indicator could be evaluated describing the yield per hectare, is the average yield of rape in an organic system.

Although the total production of rapeseed in the organic regime decreased in the two analyzed years, the area cultivated with this crop decreased more, which led to an increase of the average yield of organic rape by $10 \%$, respectively following a cultivated hectare, 1,455 kilograms were obtained in 2014, and 1927 kilos were harvested in 2015. This increase is due to an improvement in techniques and working technologies for this crop, which is an intensive growth.

Next, in order to establish the economic efficiency of rape crops is important to pay attention of the income and expense budget for rape crops both in the organic and conventional systems (Grigore et al., 2015). The indicators presented here have been calculated, for one hectare of rape, in a medium-sized plain area.

As can be seen from the budget of these crops (Tab. 3), the average yield of conventional rapeseed was set at 2500 kilograms per hectare and the organic one at 1700 kilograms per 
Table 3. Revenue and expense budget for conventional and organic rapeseed crops

\begin{tabular}{|c|c|c|c|}
\hline \multirow{2}{*}{ INDICATORS } & \multirow{2}{*}{ U.M } & \multicolumn{2}{|c|}{ Culture System } \\
\hline & & Conventional & Organic \\
\hline Average production & $\mathrm{kg} / \mathrm{ha}$ & 2500 & 1700 \\
\hline A. VALUE OF PRODUCTION & lei & 4402.5 & 3638 \\
\hline A1. Of which the main production & lei & 4162.5 & 3638 \\
\hline B (+) SUBVENTIES & lei & 733.6 & 1714.5 \\
\hline C (=) GROSS PRODUCT & lei & 5136.1 & 5352.5 \\
\hline D (-) TOTAL EXPENSES & lei & 4204 & 2641 \\
\hline D1. Of which for the main production & lei & 3964 & 2641 \\
\hline I. VARIABLE CHARGES & lei & 3331.2 & 2259.4 \\
\hline 1.Expenditure on raw materials and materials & lei & 1891.3 & 1009.2 \\
\hline - Seed and planting material & lei & 320 & 200 \\
\hline -Chemical / organic fertilizers & lei & 459 & 804.5 \\
\hline - Pesticides / Organic pesticides & lei & 642.1 & 4.7 \\
\hline - Other materials & lei & 470.2 & 0 \\
\hline 2. Expenditure on mechanized works & lei & 1285.6 & 1158.7 \\
\hline 3. Spending on irrigation & lei & $\mathrm{x}$ & $\mathrm{x}$ \\
\hline 4. Supply costs & lei & 56.7 & 30.3 \\
\hline 5. Temporary labour costs * & lei & $\mathrm{x}$ & $\mathrm{x}$ \\
\hline 6. Insurance & lei & 97.6 & 61.2 \\
\hline II. FIXED EXPENSES & lei & 872.6 & 381.4 \\
\hline - Expenditure on permanent labour & lei & 670.2 & 248 \\
\hline - General and management expenses & lei & 78.1 & 48.9 \\
\hline - Loan interest & lei & 81.3 & 41.5 \\
\hline - Arenda & lei & $\mathrm{x}$ & $\mathrm{x}$ \\
\hline -Entertainment for buildings and utilities & lei & 43 & 43 \\
\hline E. (=) IMPORTANT INCOME & lei & 198.7 & 997.3 \\
\hline$(-)$ Taxes and fees & lei & 31.8 & 159.6 \\
\hline$(-)$ Rental & lei & $\mathrm{x}$ & $\mathrm{x}$ \\
\hline F. (=) NET INCOME + subsidies & lei & 900.5 & 2552.2 \\
\hline G. TAX INCOME TAX (\%) & $\%$ & 5.0 & 37.8 \\
\hline H. NET INCOME RATE + Subsidies (\%) & $\%$ & 22.7 & 96.6 \\
\hline COST OF PRODUCTION & lei/to & 1586 & 1553 \\
\hline PREVIOUS PRICE MARKET PRICE & lei/to & 1665 & 2140 \\
\hline
\end{tabular}

Source: ADER Project 13.1.2

hectare was 32 percent lower than first. However, considering the value of production, it can be observed that the differences are not so great, the value of organic production being $17.3 \%$ lower than the conventional one. Taking into account the above mentioned production gap, the reason for this difference, not very discrepant, is given by the price of capitalization of production, organic production having a higher market price compared to the conventional one by about $28.5 \%$.

Concerning the rape crop costs for the two systems, it is noted that in the case of organic rape, the total expenditure is lower than in the conventional system. These expenses, in amount 

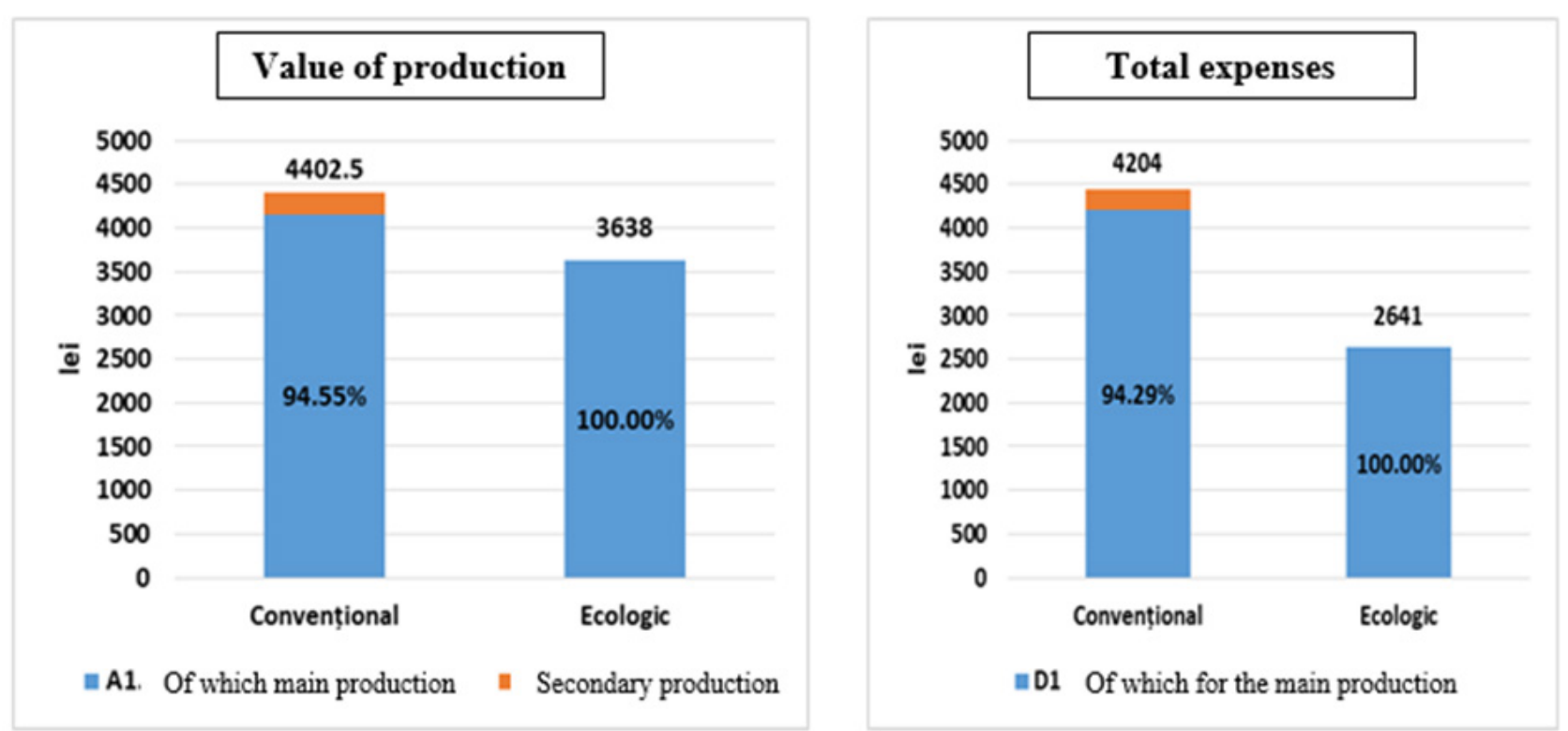

Figure 3. Structure of production value and expenditure Source: own processing based on BVC data ADER Project 13.1.2

of 2641 lei, are fully used for the production of seeds. This effort is lower with $37.2 \%$ compared to conventional production costs.

The later one is done with an effort of 4204 lei, out of which $94.29 \%$ (3964 lei) for the main production (rapeseed) and the remaining 240 represents the value of the secondary production.

Analyzing the structure of expenditures it can be seen that for conventional rapeseed culture, from the 4204 lei spent to obtain 2500 kilograms of production, $79.24 \%$ (3331 lei) are variable expenses and $20.76 \%$ (873 lei) represent the level of fixed costs. In the case of organic production, 85.56\% (2259 lei) are variable expenditures and $14.44 \%$ (382 lei) are fixed expenditures.

Analyzing in comparison with the value of production, it can be noticed that for the rape cultivated in a conventional system, the expenditures almost reach the point of profitability, so for this production there was a taxable income of only 198.7 lei; and even if the value of organic production is lower, the expenses are lower compared to this, which led to a taxable income obtained by the farmer, which produced rape in organic regime, of 997.3 lei.

At these income levels the tax rate was applied, but the subsidies to this crop were added, favoring the organic farming system, where higher subsidies were found.

Rates of return help to establish economic efficiency, so for conventional rapeseed crops, the taxable income rate was $5 \%$ and the organic system $37.8 \%$. By adding the grant, these rates of return automatically increase, but the difference

Table 4. Indicators on the economic efficiency of rape culture in a conventional and organic system

\begin{tabular}{|c|c|c|c|}
\hline \multirow{2}{*}{ INDICATORS } & \multirow{2}{*}{ U.M } & \multicolumn{2}{|c|}{ Culture System } \\
\hline & & Conventional & Organic \\
\hline Gross margin & lei & 831.3 & 1378.7 \\
\hline Expenses for 1000 lei production pp. & lei & 952.3 & 725.9 \\
\hline Consumption of working time & man-hours / ha & 103.1 & 42.3 \\
\hline Labour productivity (value) & lei / hour-man & 40.4 & 86.0 \\
\hline Work productivity (physical) & $\mathrm{Kg} / \mathrm{h}-\mathrm{man}$ & 24.2 & 40.2 \\
\hline Profit or loss (gross) & lei / ha & 198.7 & 997.3 \\
\hline Profit threshold (physical) & $\mathrm{kg}$ & 2380.7 & 1234.0 \\
\hline
\end{tabular}




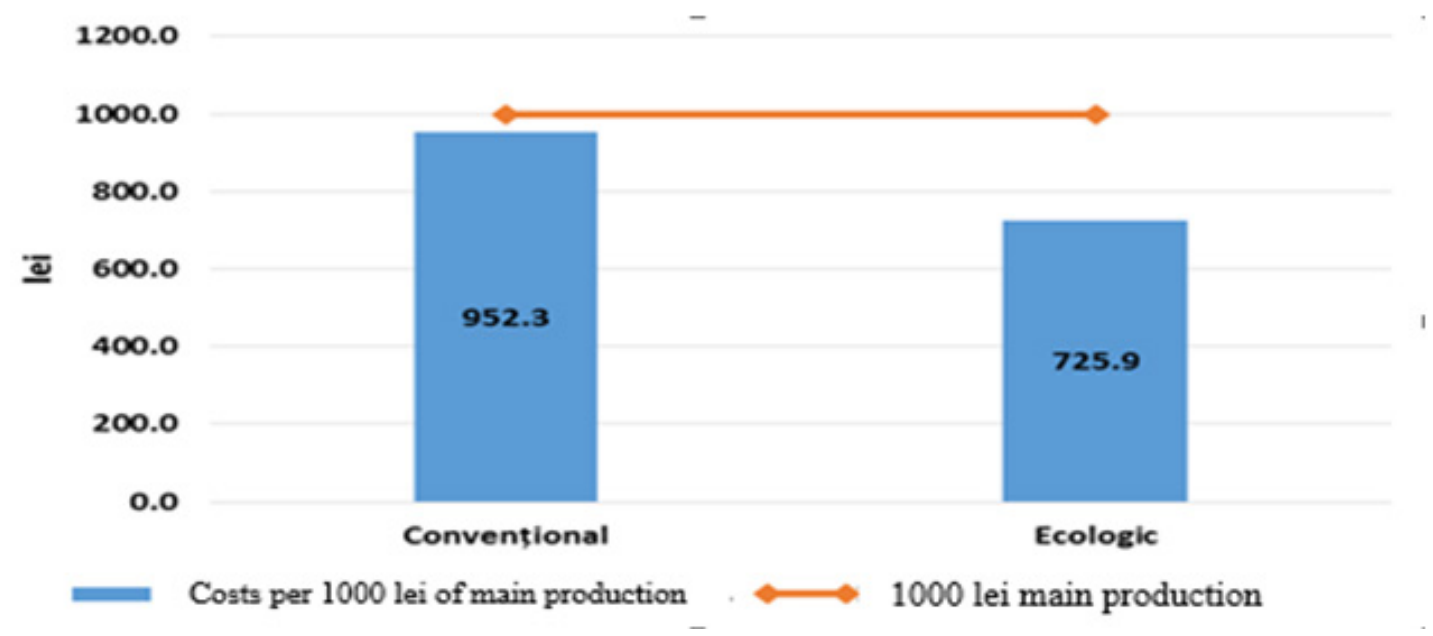

Figure 4. Costs per 1000 lei of main production Source: own data processing ADER Project 13.1.2

remains clear, or even accentuated, to the organic system.

Analyzing the cost per unit of product, in our case per ton, can be considered to be almost the same, a tons of rapeseed in the classic system cost 1586 lei, and one in the organic system was less expensive by 33 lei (1553 lei/ton), but as mentioned, the recovery price is higher for organic rape.

In order to better determine the feasibility and economic efficiency of this culture, both in conventional and organic systems, the following indicators were calculated (Tab. 4).
The "gross margin" indicator was determined, making the difference between the value of the main production and the variable costs of rapeseed crops, both conventional and organic. As can be seen in Table 4, the gross margin of rapeseed in the organic system is higher than that of conventional rapeseed, the main reason is that in organic farming, the substances administered for plant care are significantly lower and implicitly their cost is very low, which has led to a lower level of variable costs than in the case of agriculture characterized by chemical treatments. Therefore, the gross margin of the rape crop in the organic

\section{Work productivity (physical)}

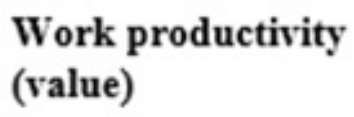

Consumption of working time

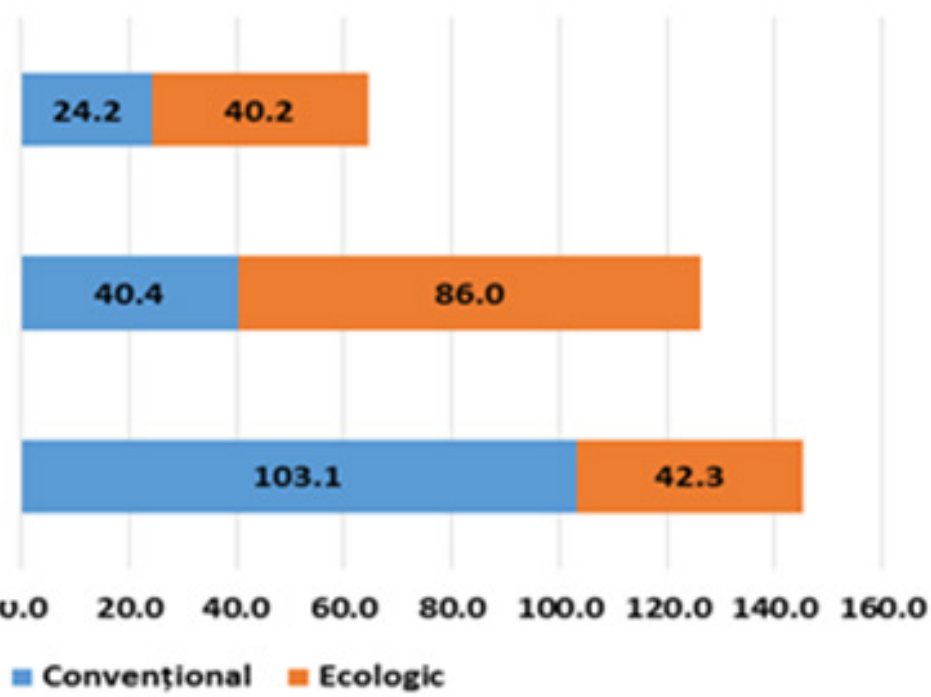

Figure 5. Consumption of working time and labor productivity Source: own data processing ADER Project 13.1. 


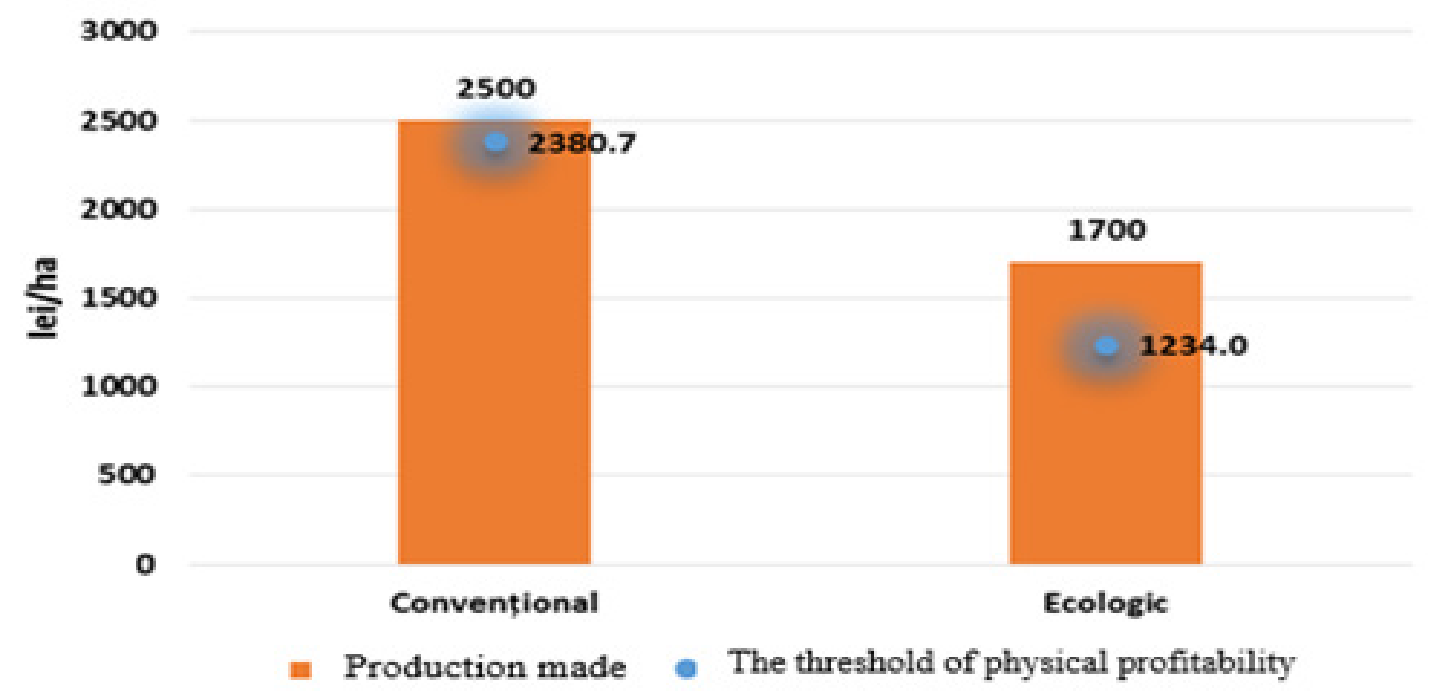

Figure 6. The physical profitability threshold Source: own data processing ADER Project 13.1.2

system was 1378.7 lei, $65.8 \%$ higher than the one in the conventional system (831.3 lei).

The second indicator, "cost per 1000 lei of main production", determines the degree of allocation of production factors, in order to obtain the finished product, in this case the rape seed. Thus, in order to be able to as easily ascertain the effect of this indicator on the economic efficiency of culture, we will present it in the following graph.

As can be seen from the previous figure, for rape crops irrespective of the system used, the expenses per 1000 lei of main production are below this threshold, meaning that on any of the two systems the farmer would choose, he will gain profit, but not at the same level. In the case of conventional rape culture, to produce rapeseed in the value of 1000 lei, 952,3 lei were spent, and the difference is only very low of only 47,7 lei. In the case of organic rape, where the costs are significantly lower, 725.9 lei were spent to produce organic rape worth 1000 lei, the difference being 274.1 lei, about 5.7 times higher than the previous culture system.

In Figure 5 differences in working time consumption can be observed, so for conventional rape crops for seed production, this consumption was 103.1 hours per person, and the consumption of working time per hectare of organic rape was lower by about $59 \%$ and 42.3 hours respectively. The main reason for this difference is that in organic farming, treatments and other substances or materials are not used in the care of plants, hence, implicitly, and manual labor force.

For these reasons, both labor and productivity can be explained, depending on the output obtained and its value. Therefore, the productivity of work physically expressed is higher in the organic system (40.2 kg/h-man) compared to the conventional system $(24.2 \mathrm{~kg} / \mathrm{h}-\mathrm{man})$ by $66.1 \%$. In the case of labor productivity in terms of value, a similar situation is observed, as mentioned above, due to the reduced labor consumption in the case of the organic crop system, it is noticed that the productivity of the work for the organic rapeseed was 86 lei/hour-man, and in the case of conventional agriculture, a man produced in one hour 40.4 lei, a difference of 2.12 times.

In Figure 6 it can be seen the profitability threshold for both conventional and organic farming systems. Regarding conventional rapeseed, the production of 2500 kilograms was very little above the profitability threshold of 2380.7 kilograms so that the farmer's profit is almost 120 kilograms of rapeseed per hectare. In the case of organic rape production, due to the lower costs and the higher price, a profitability threshold was set in lower physical units, 1234 kilograms per hectare. Thus this level of production was easily exceeded the production in this case was 1700 kilograms of organic rape. Thus, the difference of 466 kilograms of rapeseed is left to the farmer, considering it to be a profit. 


\section{Conclusion}

The first part of this study presents the areas planted with rape which either in conventional or organic systems, during the analyzed periods were reduced, but meanwhile the average yield per hectare was increasing for each crop system, which implies an intensive production increase. Consequently average conventional rapeseed production was $2107 \mathrm{~kg} / \mathrm{ha}$ compared to the 1836 $\mathrm{kg} / \mathrm{ha}$ organic system, the difference between these two yields being quite small, averaging $14.76 \%$ at the expense of conventional agriculture.

Regarding economic efficiency, both crop systems bring profit to the farmer, but in terms of its value, only the rape obtained in the organic regime is profitable. From the revenues and expenditure budget, it can be noticed that the value of the gross profit for organic agriculture is below the 200 lei level, but that for conventional agriculture is approaching 1000 lei.

Due to the better harvesting price for organic rape, it can be seen that for a $32 \%$ lower production compared to the conventional one, the production value of rape in the organic system is only $17.36 \%$ lower. In terms of total expenditure, given the same production gap $(2500 \mathrm{~kg} / \mathrm{ha}$, compared to 1700 $\mathrm{kg} /$ ha of organic production), the level of organic production is lower than the yield difference, i.e. total organic rape are lower by $37 \%$ compared to those with conventional production.

In all the aspects studied in order to determine the economic efficiency, there has been observed that both production systems bring profit, but the rates of profitability are quite different, in the case of classical agriculture, rapeseed yielded a rate of only $5 \%$, which does not fully ensure the profitability of the culture, in organic farming rapeseed had a rate of profitability of over 30\% (37.8\%), which leads to the fact that this culture, used in this system, is a solution for increasing the farmer's income. Consequently, to avoid certain risks, the farmer must take care of all the cost elements of the conventional crop and increase the production level, because an imbalance of only 120 pounds per hectare, can make the difference between gain and loss. Therefore, the farmer should consider the passage of certain land plots into a conversional system and then into a complete organic system in order to gain more from the rapeseed culture, assuming fewer risks, in terms of economic efficiency but also for improving environmental performance. According to Venkat (2012), switching from conventional farming to organic farming can provide significant opportunities to reduce greenhouse gas emissions in the coming decades by increasing carbon stockpiles in the soil, during the transition.

\section{References}

1. ADER Project 13.1.2 (2015-2018) stage 4, Technical and economic cost-orientation of production costs and estimates of harvest prices for wheat, barley, maize, sunflower, rapeseed, soybeans, sugar beet, rice, hemp, hops, tobacco, conventional agriculture and organic farming"- ICEADR. www.iceadr.ro.

2. Bran M (2015). Agrophytotechnics - Cereals. Course support, Bucharest Academy of Economic Studies, Faculty of Agro-Food Economics and Environment.

3. Bunting ES (1981). Production and utilization of protein in oilseed crops, Martinus Nijhoff Publishers, Commission of the European Communities

4. De Ponti T, Rijk B, Van Ittersum MK (2012). The crop yield gap between organic and conventional agriculture. Agricultural systems (pp. 108-109).

5. Gomiero T, Pimentel D, Paoletti MG (2011). Environmental impact of different agricultural management practices: conventional vs. organic agriculture. Critical Reviews in Plant Sciences, 30 (1-2): 95-124.

6. Grigore AA, Abargaonitei SV, Nancu DV, Ghiculescu R (2015). Comparative analysis on the economic efficiency of conventional and organic agricultural products, scientific papers, vol. 51, Agronomy series, University of Agricultural Sciences and Veterinary Medicine, Iaşi

7. Isfanescu A, Robu V, Hristea AM, Vasilescu C (2015). Economic and Financial Analysis, course support, Bucharest Academy of Economic Studies, Faculty of Accounting and Management Informatics.

8. McGregorlb SE (2009). Insect pollination of cultivated crop plants (first ed. 1976), (Chapter 9) - Crop Plants and Exotic Plants - Rape.

9. National Institute of Statistics- Romania www.insse.ro, Accessed 19/01/2018

10. Organic Farming Research Institute, Germany: FiBL; www.fibl.org/en/homepage. Accessed 19/01/2018.

11. S Surcă E, Petre I (2016). Agricultura Ecologică, ISBN 978973-0-22911-0.

12. Ursu A, Șurcă E, Petre IL (2017). Indicators of Economic Efficiency for Conventional and Organic Agriculture, ASE Publishing House, Bucharest (pp. 51-58; 135-142).

13. Venkat K (2012). Comparison of twelve organic and conventional farming systems: a life cycle greenhouse gas emissions perspective. Journal of Sustainable Agriculture, 36(6): 620-649.

14. Web report of ADER 13.1.2, Phase 4, MARD- Ministry of Agriculture and Rural Development - Romania, http:// www.madr.ro/cercetare-inovare/ader-2015-2018/ader13/ 245-ader-13-1-2.html. Accessed 20/01/2018. 